\title{
RESPONSE TO ‘CONTEMPORARY DEBATES IN HEALTH IMPACT ASSESSMENT'
}

\section{Michael Staff \\ Environmental Health Branch \\ NSW Department of Health}

Harris, in the previous article, has highlighted the significant investment that has been made in developing health impact assessment (HIA) capacity within the health system. There is little doubt that the advocacy for the process has stimulated interest within the health sector and it is now time to extend that to other sectors.

The first issue Harris raises relates to how to build in or institutionalise health impact considerations in policy formation and project development. It has been demonstrated that many of the determinants of health lie outside the traditional sphere of influence of the health sector. ${ }^{1}$ Logically, it would be desirable to ensure that when a policy or project that could alter these determinants is being developed its potential health impacts are considered up front. The challenge is that the originator of the initiative is mostly likely to be outside the health sector.

One approach to institutionalising HIA outside the health sector is to couple it with other forms of impact assessment. An example of how this may work can be seen in the World Health Organization Regional Office for Europe's recent suggestion to link HIA to strategic environment assessment as a way of safeguarding human health obligations among European Union Member States. ${ }^{2}$ In NSW, whilst there is no legislative requirement for HIA to be incorporated into environmental impact statements (EISs), the process does contain administrative arrangements that can be used to ensure health impacts are addressed. These arrangements include the promotion of planning focus meetings and opportunities for government agencies to prescribe what issues they would like considered within the EIS.

The second issue that Harris has highlighted is that of matching the scope of an HIA to the reasons for it being undertaken. When considering the purpose of undertaking the HIA there is no reason why health protection (minimising risks) and health promotion objectives cannot co-exist, and indeed it would usually be of benefit to consider both these components. For example, although most EISs contain formal risk assessments for potential environmental hazards associated with a development, they also contain a social impact component. The HIA process has an in-built step to ensure that the scope of the assessment is matched to its purpose - the scoping step. There may well be some level of disagreement among participants at this stage about issues such as how to define health or what sort of evidence will be considered and this step allows an open debate about these critical issues.

The third issue that has been highlighted is the need to debate when an HIA is undertaken and at what level. Fundamental to this discussion is the need to review the effectiveness of the process. There has been considerable discussion about whether the gains achieved by employing an HIA approach can be adequately quantified..$^{3,45}$ Quantification of changes in health outcomes is comparatively rare in $\mathrm{HIA}^{3}$ and it has been suggested that the impact on the decision-making process may be a more appropriate focus of evaluation. ${ }^{6}$ To help resolve this issue, pursuing innovative approaches such as the policy/risk assessment model proposed by Joffe and Mindell ${ }^{7}$ may allow us to combine both approaches and build an evidence base for HIA.

As well as the 'What?, Why?' and 'When?' of HIA we could also add the 'Who?' HIA is a tool that has considerable potential to bring about health gains and much of the foundation to facilitate this has been laid within the health sector. To fully realise its potential and build upon the achievements made to date, advocates must develop interest and build capacity within other sectors outside health.

\section{REFERENCES}

1. Wilkinson R, Marmot M, editors. Social determinants of health: the solid facts. $2^{\text {nd }}$ ed. Copenhagen: World Health Organization, 2003.

2. Wright J, Parry J, Scully E. Institutionalizing policy-level health impact assessment in Europe: Is coupling health impact assessment with strategic environmental assessment the next step forward? Bull. World Health Organ 2005; 83(6): $472-7$.

3. Veerman J, Barendregt J, Mackenbach J. Quantitative health impact assessment: Current practice and future directions. $J$ Epidemiol Community Health 2005; 59(5): 261-70.

4. Mindell et al. What do we need for robust, quantitative health impact assessment? J Public Health Medicine 2001; 23(3): 173-8.

5. Morrison D, Petticrew M, Thomson H. Health impact assessment - and beyond. J Epidemiol Community Health 2001; 55: 219-20.

6. Quigley R, Taylor L. Evaluating health impact assessment. Public Health 2004; 118(8): 544-52.

7. Joffe M, Mindell J. A framework for the evidence base to support health impact assessment. J Epidemiol Community Health. 2002; 56(2): 132-8. 图 